\title{
Zastosowanie implantu ucha środkowego Vibrant Soundbridge w połączeniu z couplerem typu SP w przypadku przewlekłego zarostowego zapalenia ucha - opis przypadku
}

\section{The Vibrant Soundbridge middle ear implant and the SP coupler in the case of chronic otitis adhesiva - case study}

\author{
Henryk Skarżyński ${ }^{1}$, Marek Porowski ${ }^{1}$, Maciej Mrówka ${ }^{1}$, Roman Barylyak ${ }^{1}$, \\ Piotr Henryk Skarżyński ${ }^{1,2,3}$ \\ ${ }^{1}$ Instytut Fizjologii i Patologii Słuchu, Światowe Centrum Słuchu, Klinika Otorynolaryngochirurgii, \\ Warszawa/Kajetany \\ ${ }^{2}$ Instytut Narządów Zmysłów, Kajetany \\ ${ }^{3}$ Warszawski Uniwersytet Medyczny, Zakład Niewydolności Serca i Rehabilitacji Kardiologicznej, Warszawa
}

Adres autora: Henryk Skarżyński, Światowe Centrum Słuchu, ul. Mokra 17, Kajetany, 05-830 Nadarzyn, e-mail: skarzynski.henryk@ifps.org.pl

\section{Streszczenie}

Przedstawione doniesienie zawiera opis leczenia 27-letniego pacjenta z obustronnym mieszanym ubytkiem słuchu oraz całkowicie zarośniętymi przewodami słuchowymi zewnętrznymi. Jako optymalną terapię, po wcześniejszych licznych niepowodzeniach chirurgicznych polegających na braku trwałych efektów zabiegów odtwarzania światła przewodów słuchowych, wybrano zastosowanie implantu typu Vibrant Soundbridge. W tym wypadku, by uniknąć ryzyka ze strony nerwu twarzowego i wykonania szerokiej tympanotomii tylnej, zastosowano po raz pierwszy w Polsce umocowanie przetwornika FMT za pomocą couplera typu SP do trzonu i odnogi krótkiej kowadełka. Uzyskano bardzo dobry wynik progu słyszenia i rozumienia mowy.

Słowa kluczowe: implant ucha środkowego • Vibrant Soundbridge • przewlekłe zarostowe zapalenie ucha środkowego i zewnętrznego

\section{Abstract}

This report contains the description of the treatment of a 27 -year-old patient with bilateral mixed hearing loss and the absence of external ear canals. After many previous surgical failures consisted in the attempt to restore ear canals and the lack of lasting effects, the use of the Vibrant Soundbridge implant was chosen as the best possible therapy. In this case, in order to avoid a risk related to a facial nerve and extensive posterior tympanotomy, for the first time in Poland, the surgeons used the SP coupler to fix the FTM transducer to the body and short crus of the incus. The effect was a very good hearing threshold and speech understanding.

Key words: middle ear implant $\bullet$ Vibrant Soundbridge $\bullet$ chronic otitis media $\bullet$ chronic otitis externa

\section{Wstęp}

Pomimo znaczących postępów w technice chirurgicznej istnieją pacjenci, u których klasyczne operacje poprawiające słuch nie przynoszą efektu. Są to przede wszystkim osoby $\mathrm{z}$ przewlekłymi zmianami zapalnymi oraz $\mathrm{z}$ wadami wrodzonymi, z nieprawidłową anatomią aparatu przewodzącego dźwięk [1-3]. Rozwiązaniem dla nich są coraz częściej implanty ucha środkowego. Są one elektroakustycznymi urządzeniami służącymi poprawie słuchu, częściowo lub całkowicie implantowanymi do ucha środkowego [4,5]. Wśród nich szczególną pozycję zajmuje implant typu Vibrant Soundbridge (VSB), który ze względu na swoją budowę może być wykorzystywany u pacjentów zarówno z wadami wrodzonymi, jak i nabytymi ucha. Początkowo był on stosowany tylko w przypadku niedosłuchu odbiorczego, później zaczęto go stosować również $\mathrm{w}$ niedosłuchu mieszanym i w wadach wrodzonych $\mathrm{z}$ atrezją przewodu słuchowego zewnętrznego [6,7]. Pacjenci $\mathrm{z}$ niewykształconym przewodem słuchowym zewnętrznym 

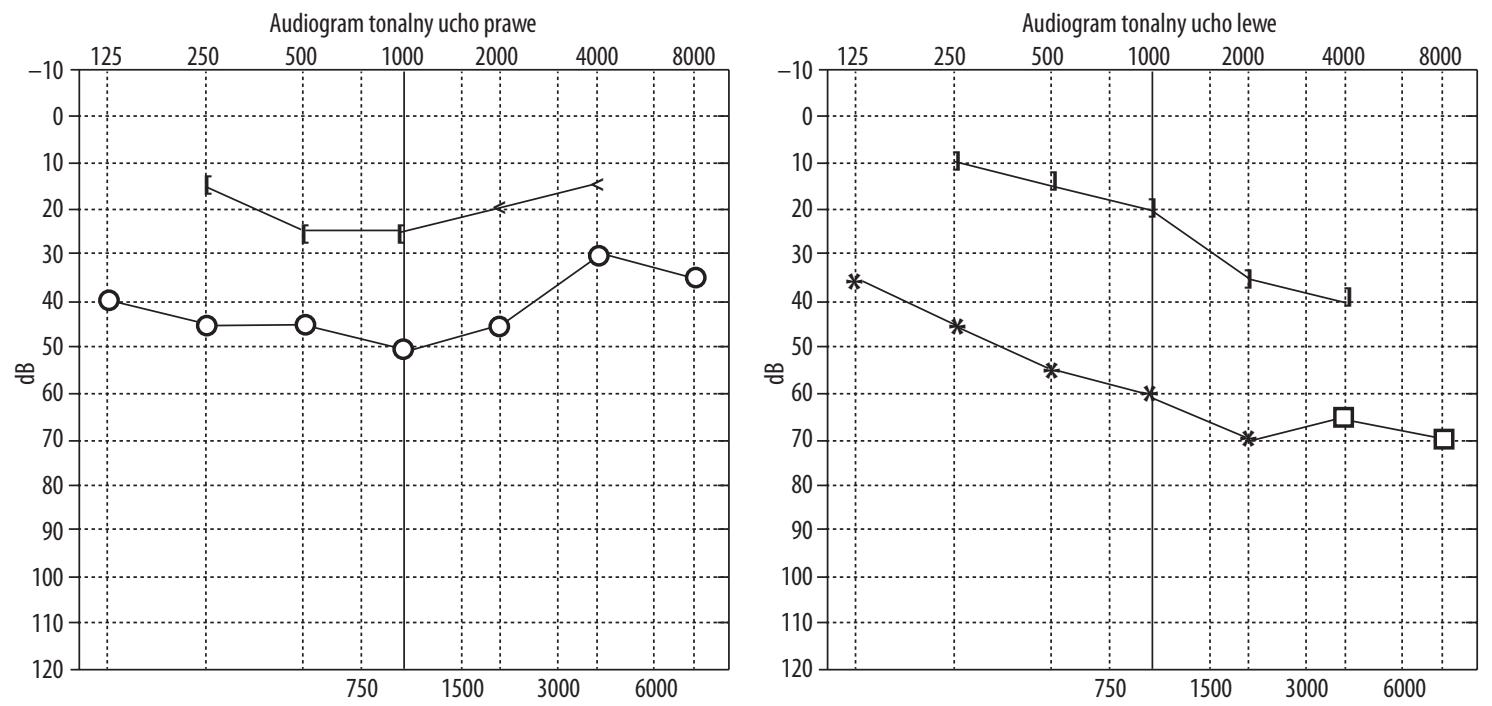

Rycina 1. Audiometria tonalna. Niedosłuch o charakterze mieszanym, bardziej nasilony w uchu lewym

Figure 1. Pure-tone audiometry. Mixed hearing loss, more severe in the left ear

lub zaawansowanymi zmianami pozapalnymi są szczególną grupą, ponieważ klasyczne aparaty słuchowe nie dają u nich dobrych efektów. Dla tej grupy najlepszym i niekiedy jedynym rozwiązaniem są implanty ucha środkowego, omijające zarośnięty przewód słuchowy.

Technika mocowania przetwornika FMT na kowadełku zakłada wykonanie tympanotomii tylnej i poprowadzenie elektrody do ucha środkowego a następnie założenie przetwornika na odnodze długiej kowadełka. Technika ta ma również swoje wady, wynikające przede wszystkim z konieczności wykonania dużej tympanotomii tylnej. Związane jest $\mathrm{z}$ tym ryzyko uszkodzenia nerwu twarzowego, struny bębenkowej, pogorszenia słuchu o typie przewodzeniowym i/lub odbiorczym, wynikajace $z$ przypadkowego uszkodzenia czy rozłączenia kosteczek słuchowych. Niekiedy wielkość jamy bębenkowej jest tak mała, że niemożliwe jest umieszczenie tam kapsuły FMT. W takich przypadkach bardzo dobrym rozwiązaniem jest zastosowanie nowych tzw. couplerów, które pozwalają na założenie przetwornika FMT na trzon kowadełka bez konieczności wykonywania tympanotomii tylnej. Praca prezentuje pierwsze w Polsce zastosowanie tej właśnie techniki u pacjenta $\mathrm{z}$ przewlekłym zarostowym zapaleniem przewodu słuchowego zewnętrznego.

\section{Materiał i metoda}

Pacjent lat 27, z obustronnym przewlekłym zarostowym zapaleniem przewodu słuchowego zewnętrznego zgłosił się do Kliniki Otorynolaryngochirurgii Instytutu Fizjologii i Patologii Słuchu w celu operacyjnego leczenia niedosłuchu. W wywiadzie ustalono, że zarastanie przewodów słuchowych następowało stopniowo od kilku lat, wraz z pogarszaniem się słuchu. Niedosłuch był obustronny, bardziej nasilony w uchu lewym, z towarzyszącymi uporczywymi szumami usznymi. Pacjent był już wielokrotnie operowany na oboje uszu w różnych ośrodkach. Po operacjach następowała krótkotrwała poprawa słuchu, po czym dochodziło do ponownego zarastania przewodu słuchowego zewnętrznego i pogarszania słuchu. W badaniu

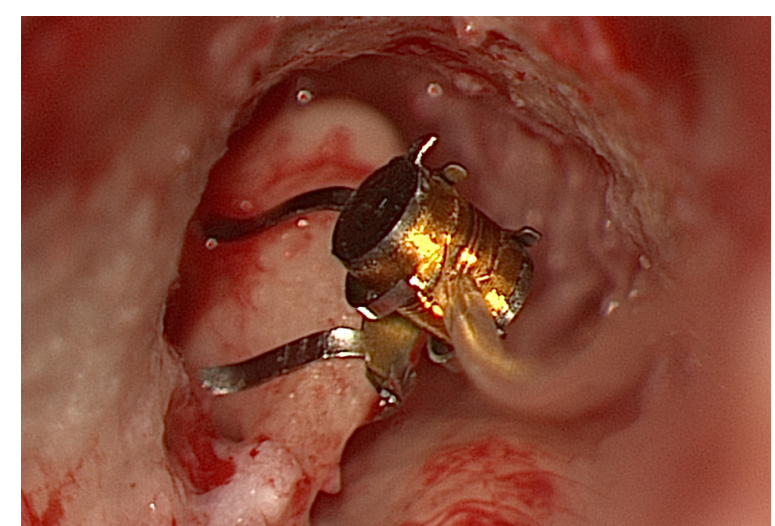

Rycina 2. Zdjęcie śródoperacyjne. Przetwornik FMT założony na coupler typu SP, a ten na trzon kowadetka

Figure 2. Intraoperative image. The FTM transducer on the SP Coupler attached to the body of the incus

przedmiotowym stwierdzono obustronne całkowite zarośnięcie przewodu słuchowego zewnętrznego. Badania dodatkowe wykazały obustronny niedosłuch o charakterze mieszanym (rycina 1).

Z uwagi na fakt, że wcześniejsze liczne operacje, którym poddał się pacjent, nie przyniosły spodziewanego długotrwałego efektu, zaproponowano mu wszczepienie implantu ucha środkowego omijającego niedrożny przewód i stymulującego bezpośrednio łańcuch kosteczek słuchowych. Do operacji wybrano stronę lewą. Było to podyktowane większą rezerwą ślimakową w tym uchu oraz lepszymi wrażeniami słuchowymi pacjenta w próbach symulacyjnych wykonanych przed operacją. Zabieg przeprowadzono w grudniu 2014 r. Z dojścia zausznego wykonano ograniczone otwarcie wyrostka sutkowatego. Pobrano dłutem płaskim fragment warstwy korowej kości. Następnie poszerzono od tyłu wejście do attyki i dobrze uwidoczniono odnogę krótką i trzon kowadełka oraz główkę młoteczka. $\mathrm{Na}$ odnodze krótkiej kowadełka i trzonie zapięto coupler typu SP a następnie - po odcięciu zaczepu - przetwornik implantu (FMT). Wejście do jamy wyrostka wypełniono 


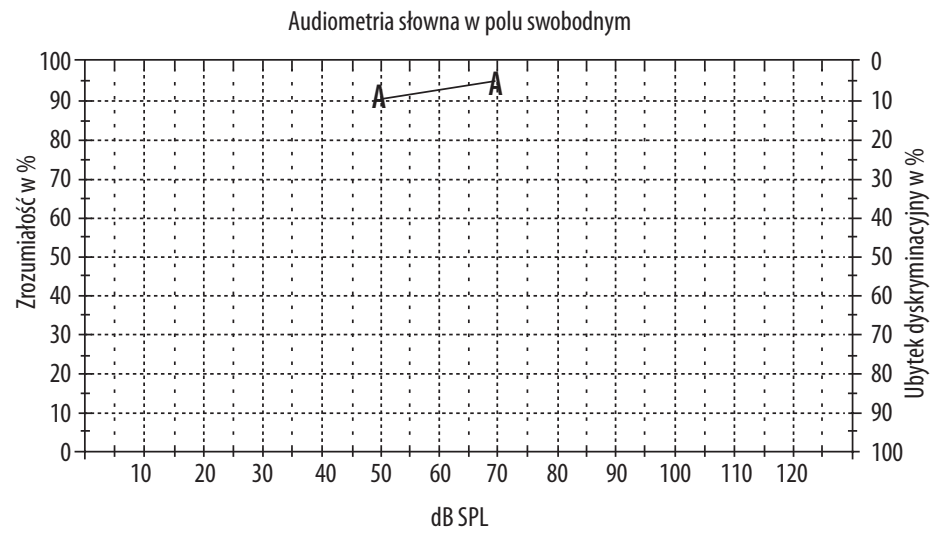

Rycina 3. Audiometria słowna w polu swobodnym po założeniu implantu

Figure 3. Free field word audiometry of a patient with an implant

Spongostanem nasączonym antybiotykiem, przykryto klejem tkankowym i pobraną wcześniej płytką kostną. Części wewnętrzne implantu umocowano w loży kostnej przygotowanej na powierzchni kości skroniowej. Założono szwy na powięź i skórę oraz opatrunek zewnętrzny. Zasadniczy etap operacji, a więc założenie przetwornika FMT na trzon kowadełka, przedstawiono na rycinie 2. Przebieg okołooperacyjny był bez powikłań, pacjent następnego dnia po zabiegu został wypisany do domu. Podczas wizyty kontrolnej stwierdzono prawidłowe gojenie rany pooperacyjnej. Po miesiącu zostało wykonane badanie audiometryczne potwierdzające brak zmian zarówno przewodnictwa kostnego, jak i powietrznego oraz został podłączony procesor zewnętrzny implantu. Subiektywne odczucia pacjenta po pierwszych próbach były bardzo dobre. Wyniki audiometrii słownej w polu swobodnym wykonanej u niego 3 miesiące po zabiegu przedstawiono na rycinie 3 .

\section{Omówienie wyników}

Implant typu Vibrant Soundbridge jest rozwiązaniem bezpiecznym i uniwersalnym, mogącym mieć zastosowanie w przypadkach niedosłuchu odbiorczego, przewodzeniowego i mieszanego $[4,5,8]$. Konieczność wykonania tympanotomii tylnej w celu założenia przetwornika FMT na kowadełku stanowi niejednokrotnie dużą przeszkodę. Trudności wynikają z uwarunkowań anatomicznych, możliwości wykonania tylko małej tympanotomii tylnej, nieprawidłowego przebiegu nerwu twarzowego, obecności innych wad wrodzonych ucha środkowego oraz faktu, że sam przetwornik FMT jest dość duży - ma wymiary $2,3 \times 1,8 \mathrm{~mm}$ i masę około $25 \mathrm{mg}$. Oznacza to, że tympanotomia tylna musi być co najmniej tak duża, aby można było przemieścić przetwornik do jamy bębenkowej i bezpiecznie go zapiąć na odnodze długiej kowadełka. Nie zawsze wykonanie takiej tympanotomii jest możliwe, gdyż w niektórych przypadkach poszerzając znacznie jej wielkość, można doprowadzić do uszkodzeń nerwu VII i samych kosteczek słuchowych, co skutkuje najczęściej zaburzeniami smaku, niedowładem nerwu VII lub pogorszeniem słuchu [9-11]. Całkowite porażenie nerwu twarzowego jako bezpośrednie powikłanie jest na szczęście bardzo rzadkie.

Vibrant Soundbridge początkowo był przeznaczony do stosowania w przypadku niedosłuchu zmysłowo-nerwowego i posiada zapięcie przeznaczone do mocowania na odnodze długiej kowadełka. Jego zakończenie nie nadaje się do zakotwiczania na trzonie kowadełka, ponieważ może łatwo zsuwać się. Aby uniknąć wykonywania tympanotomii tylnej w sytuacjach grożących powikłaniami, opracowano specjalne couplery. Coupler taki łączy się z przetwornikiem FMT po odcięciu jego własnego zapięcia, a następnie zakłada na trzon kowadełka, niejako zatrzaskując całość na nim (rycina 2). Możliwość samoistnego zsunięcia się takiego couplera jest teoretycznie bardzo mała. Przedstawiony przypadek jest pierwszym tego typu w Polsce i jednym z nielicznych na świecie, dlatego nie było możliwości odniesienia się do innych tego typu operacji w dostępnym piśmiennictwie. Niemniej krótszy czas zabiegu, brak ryzyka dla nerwu twarzowego i struny bębenkowej oraz tylko minimalne teoretyczne ryzyko uszkodzenia kosteczek słuchowych - w porównaniu z klasyczną operacją - pozwalają przypuszczać, że zastosowanie implantu VSB w konfiguracji z couplerem typu SP jest dobrym rozwiązaniem.

\section{Wnioski}

Zastosowanie implantu VSB $\mathrm{w}$ połączeniu $\mathrm{z}$ couplerem typu SP jest obiecującym sposobem poprawy słuchu u pacjentów, u których przewiduje się zakotwiczenie przetwornika FMT na kowadełku. Może to być postępowanie z wyboru, zwłaszcza w sytuacjach zarośnięcia lub niewykształcenia przewodu słuchowego zewnętrznego i niedorozwoju ucha środkowego lub w przypadku zmian zarostowych ucha zewnętrznego.

\section{Piśmiennictwo:}

1. Caruz ADL, Linthcum FH, Luxford WM. Congenital atresia of the external auditory canal. Laryngoscope, 1985; 95: 421-7.

2. Declau F, Cremers C, Van de Heyning P. Diagnosis and management strategies in congenital atresia of the external auditory canal. Br J Audiol, 1999; 33(5): 313-27.
3. Olszewski Ł, Ratuszniak A, Obrycka A, Porowski M, Skarżyński PH, Pastuszak A, Skarżyński H. Middle Ear Implant - a chance for elimination of certain restrictions on sound reception tied with the hearing aids in the partial deafness treatment. 10 ${ }^{\text {th }}$ ESPCI Athens, Medimond, 2011, 21-8. 
4. Boeheim K. Active Middle Ear Implants. Advances in Oto-Rhino-Laryngology, 2010; 69.

5. Tysome JR, Moorthy R, Lee A, Jiang D, O’Connor AF. Systematic review of middle ear implants: do they improve hearing as much as conventional hearing aids? Otol Neurotol., 2010; 31(9): 1369-75.

6. Kiefer J, Arnold W, Staudenmaier R. Round window stimulation with an implantable hearing aid (Soundbridge) combined with autogenous reconstruction of the auricle - a new approach. ORL J Otorhinolaryngol Relat Spec, 2006; 68(6): 378-85.

7. Frenzel H, Hanke F, Beltrame M, Steffen A, Schonweiler R, Wollenberg B. Application of the Vibrant Soundbridge to unilateral osseous atresia cases. Laryngoscope, 2009; 119(1): 67-74.
8. Skarżyński H, Olszewski Ł, Skarżyński P, Lorens A, Piotrowska A, Porowski M i wsp. Direct Round Window Stimulation with the Vibrant Soundbridge (Med-El): 5-years experience using technique without fascia. Eur Arch Otorhinolaryngol, 2014; 271(3): 477-82.

9. McManus LJ, Stringer MD, Dawes PJ. Iatrogenic injury of the chorda tympani: a systematic review. J Laryngol Otol, 2012; 126(1): 8-14.

10. Fraysse B, Lavieille JP, Schmerber S, Enee V, Truy E, Vincent C i wsp. A multicenter study of the Vibrant Soundbridge middle ear implant: early clinical results and experience. Otol Neurotol, 2001; 22(6): 952-61.

11. Sterkers O, Boucarra D, Labassi S, Bebear JP, Dubreuil C, Frachet B i wsp. A middle ear implant, the Symphonix Vibrant Soundbridge: retrospective study of the first 125 patients implanted in France. Otol Neurotol, 2003; 24(3): 427-36. 